\title{
Decline of melanism in two British moths: spatial, temporal and inter-specific variation
}

\author{
LM Cook $^{1}$ and JRG Turner ${ }^{2}$ \\ ${ }^{1}$ The Manchester Museum, University of Manchester, Manchester, UK and ${ }^{2}$ Institute of Integrative and Comparative Biology, Faculty of \\ Biological Sciences, University of Leeds, Leeds, UK
}

\begin{abstract}
The decline in industrial melanism over the last quarter century constitutes an exceptional case of an evolutionary change, varying in both time and space, and between species. In Biston betularia and Odontoptera bidentata, the change in melanic frequency is closely replicated at two sites $0.5 \mathrm{~km}$ apart. Between seven sites $50-100 \mathrm{~km}$ apart, there is heterogeneity in both the speed and timing of change. At sites that were heavily industrialized, the change is faster, from an initially higher frequency, and starts later than at sites which are more rural.
\end{abstract}

We propose a method for estimating systematic change during sigmoid declines in melanic frequencies. This fails to show any significant change over time in selective coefficients. It is concluded that the overall pattern of change has been driven largely by events in the most polluted and industrialized parts of the country. Although migration may contribute to the estimated selective values, natural selection is the only credible explanation for the overall decline. Heredity (2008) 101, 483-489; doi:10.1038/hdy.2008.105; published online 22 October 2008

Keywords: industrial melanism; peppered moth; selection curve; selective coefficient; systematic change; spatial scale

\section{Introduction}

The relevance, and even reliability, of research on industrial melanism has recently been subjected to a series of determined challenges (Wells, 2000; Hooper, 2002; see also Rudge, 2003; Majerus, 2005; de Roode, 2007). In such circumstances, replication of results, always a staple of scientific work (for example, Turner, 2002), assumes even greater importance. We show here that in two species of moth-Biston betularia (L.) and Odontoptera bidentata (Clerck) - the decline in the frequencies of industrial melanics over the last quarter century is closely replicated at two independent but adjacent sites. We also show that as the scale of sampling is expanded, first by two orders of magnitude and then countrywide, the process of change becomes heterogeneous in time and space, and that it differs between the species.

Industrial melanism in moths was brought to the attention of the scientific community by Bateson (1900), who noted the Mendelian nature of the genetic variation. Melanic forms increased in frequency in many species of moths during the first half of the nineteenth century, starting in industrialized north-west England (Doncaster, 1906). A little later, Haldane (1924, 1932) demonstrated that the rate of increase in frequency of the carbonaria form of the peppered moth $B$. betularia required the action of very strong selection. In the mid-twentieth century, Kettlewell (1973) established the geographical distribution of melanic forms of this species, and carried

Correspondence: Dr LM Cook, The Manchester Museum, University of Manchester, Oxford Road, Manchester M13 9PL, UK.

E-mail:lcook@manchester.ac.uk

Received 9 January 2008; revised 2 September 2008; accepted

9 September 2008; published online 22 October 2008 out experiments that implicated predation by birds as a selective factor. By the 1970s, effects of industrial pollution on the atmosphere and background were lessening and there were signs that melanic frequencies had started to decrease (for review, see Kettlewell, 1973; Majerus, 1998; Cook, 2003). The subject became a part of evolutionary science in the 1920s and 1930s with the recognition, stemming from Punnett (1915) and formally developed by Wright (1931), that evolution could be described as changes in gene frequency. Change may come about by chance, or may be driven by the three systematic processes of mutation, migration and selection. Thus, even if we cannot describe selection precisely, it must be involved if the other processes can be rejected as the principal causative agents.

\section{Materials and methods}

A mercury vapour moth trap was used by JRGT to collect the two species of moths at a site in a suburban location north of the industrial (now postindustrial) city of Leeds (JRGT site, NGR (national grid reference) 434484 439851). This is $476 \mathrm{~m}$ away from the collecting site used by SL Sutton (SLS site, NGR 434379 439387) and previously reported (Cook et al., 2005), allowing frequencies in parallel samplings to be compared. In the peppered moth $B$. betularia, the black form carbonaria, intermediates insularia and the black and white typica forms are scored, and in the scalloped hazel moth $O$. bidentata, the melanic nigra and the pale brown nonmelanic forms are scored. Descriptions of these phenotypes are given by Kettlewell (1973). Evidence on the number of alleles in the melanic series in $B$. betularia is reviewed by Cook and Muggleton (2003). Both moths have a single generation per year, and the collection by 
JRGT extends from 1984 to 2006. Two samples of B. betularia taken by JRGT in York (NGR 462450) in 1966 and 1970 are also reported to augment the series collected by TJ Crawford from 1990 to 2004 (Cook et al., 2005).

\section{Results}

Data

The samples obtained by the two collectors from 1984 are given in Table 1 . In $B$. betularia, the intermediate insularia forms are rare in the region and were not separated by SL Sutton, but combined with typicals. However, carbonaria frequencies can be compared in the two data sets, as can the nigra frequencies in $O$. bidentata. Although yearly sampling effort was not controlled by either collector, the total number of $B$. betularia individuals caught at the two sites is correlated (Spearman's $R=0.783, P<0.001$ ), suggesting that the variation in sampling success reflects natural variation in abundance. This is not so for O. bidentata $(R=0.335, P>0.05)$. Catch size in this, less mobile, species could be sensitive to differing microclimates around the traps.

Because of small numbers in some years samples from 1984 to 2006 have been grouped into successive periods (Table 2). To test for between-site variation in the frequency of carbonaria, a heterogeneity $\chi^{2}$ has been calculated for each row in Table 2 (from $2 \times 2$ tables, each having 1 d.f.). Neither these seven values individually, nor their sum $\left(\chi^{2}=4.78,7\right.$ d.f., $\left.P>0.5\right)$ is significant. In addition, the $\chi^{2}$ for the total of the whole period $\left(\chi^{2}=1.49,1\right.$ d.f., $\left.P>0.2\right)$ and (by difference) the heterogeneity $\chi^{2}$ (measuring the extent to which individual year groups might differ from each other in the way carbonaria was associated with one or other site; $\chi^{2}=3.29$, 6 d.f., $P>0.7)$ are both insignificant. On all three criteria, the sites are therefore sampling the same statistical (and arguably Mendelian) population, and it is valid to pool the results for both sites. The heterogeneity measuring change (yearly) is $\chi^{2}=235.16$ (from a $2 \times 7$ contingency table, 6 d.f., $P \ll 0.001$ ), almost all because of a progressive decline in carbonaria frequency. Likewise, with $O$. bidentata the overall intersite heterogeneity is not significant $\left(\chi^{2}=0.0001,1\right.$ d.f., $\left.P>0.99\right)$, neither is the heterogeneity between periods $\left(\chi^{2}=3.52,7\right.$ d.f., $\left.P>0.8\right)$, nor the sum of the individual $\chi^{2}\left(\chi^{2}=3.52,8\right.$ d.f., $\left.P>0.8\right)$; therefore, as with betularia, the sites are statistically indistinguishable and can be pooled. The decline in melanic frequency is less marked and less consistent than in $B$. betularia $\left(\chi^{2}=17.54,7\right.$ d.f., $\left.P \sim 0.02\right)$.

Very few individuals of the insularia forms of $B$. betularia were seen. The only time they occurred on successive occasions was 1988-1991, when they were present in smaller total samples than had been obtained during the previous 5 years. Thus carbonaria declined progressively over the period studied, whereas insularia may have increased in frequency then dropped again.

Table 1 Data on melanic moths caught in north Leeds

\begin{tabular}{|c|c|c|c|c|c|c|c|c|c|}
\hline \multirow[t]{3}{*}{ Date } & \multicolumn{5}{|c|}{ JRGT site } & \multicolumn{4}{|c|}{ SLS site } \\
\hline & \multicolumn{3}{|c|}{ Biston betularia } & \multicolumn{2}{|c|}{ Odontoptera bidentata } & \multicolumn{2}{|c|}{ B. betularia } & \multicolumn{2}{|c|}{ O. bidentata } \\
\hline & $M^{c}$ & $M^{i}$ & $M^{t}$ & $C^{n}$ & $C^{n m}$ & $M^{c}$ & $M^{t}+M^{i}$ & $C^{n}$ & $C^{n m}$ \\
\hline 1984 & 31 & 1 & 5 & 5 & 3 & 27 & 1 & 21 & 18 \\
\hline 1985 & 35 & 0 & 5 & 4 & 5 & 48 & 5 & 17 & 12 \\
\hline 1986 & 96 & 2 & 6 & 11 & 5 & 83 & 3 & 23 & 13 \\
\hline 1987 & 29 & 0 & 2 & 6 & 10 & 12 & 1 & 14 & 13 \\
\hline 1988 & 48 & 2 & 6 & 11 & 17 & - & - & - & - \\
\hline 1989 & 10 & 4 & 1 & 9 & 6 & - & - & - & - \\
\hline 1990 & 14 & 2 & 2 & 6 & 10 & 5 & 2 & 2 & 3 \\
\hline 1991 & 10 & 1 & 5 & 1 & 1 & 34 & 16 & 3 & 18 \\
\hline 1992 & 6 & 0 & 5 & 1 & 4 & 27 & 9 & 16 & 20 \\
\hline 1993 & 10 & 0 & 6 & 4 & 2 & 18 & 11 & 11 & 7 \\
\hline 1994 & 2 & 0 & 2 & 0 & 0 & 7 & 11 & 4 & 2 \\
\hline 1995 & 3 & 0 & 6 & 4 & 2 & 1 & 5 & 3 & 4 \\
\hline 1996 & 2 & 0 & 1 & 0 & 0 & 4 & 1 & 5 & 7 \\
\hline 1997 & 2 & 0 & 2 & 0 & 0 & 2 & 1 & 0 & 0 \\
\hline 1998 & 3 & 0 & 3 & 4 & 3 & 1 & 8 & 1 & 3 \\
\hline 1999 & 5 & 2 & 14 & 3 & 5 & 9 & 13 & 10 & 10 \\
\hline 2000 & 3 & 0 & 3 & 1 & 2 & 6 & 18 & 11 & 18 \\
\hline 2001 & 1 & 0 & 6 & 3 & 4 & - & - & - & - \\
\hline 2002 & 0 & 0 & 4 & 0 & 3 & - & - & - & - \\
\hline 2003 & 0 & 0 & 0 & 0 & 1 & 1 & 15 & 8 & 16 \\
\hline 2004 & 0 & 0 & 1 & 0 & 1 & - & - & - & - \\
\hline 2005 & 1 & 0 & 2 & 4 & 2 & - & - & - & - \\
\hline 2006 & 1 & 0 & 2 & 0 & 0 & - & - & - & - \\
\hline \multicolumn{10}{|c|}{ JRGT York } \\
\hline 1966 & 26 & 0 & 1 & 1 & 1 & & & & \\
\hline 1970 & 29 & 0 & 0 & 0 & 0 & & & & \\
\hline
\end{tabular}

Abbreviations: $\mathrm{C}^{\mathrm{n}}$, nigra; $\mathrm{C}^{\mathrm{nm}}$, non-melanic; $\mathrm{M}^{\mathrm{c}}$, carbonaria; $\mathrm{M}^{\mathrm{i}}$, insularia; $\mathrm{M}^{\mathrm{t}}$, typical; $\mathrm{NGR}$, national grid reference.

Left: numbers of melanic and typical morphs in B. betularia and O. bidentata at location NGR 434484439851 . Two samples from York (NGR 462450) are also appended. Right: numbers of morphs in the same species collected by Dr SL Sutton at NGR 434379439387 and reported in Cook et al. (2005). 
Table 2 Heterogeneity between sites

\begin{tabular}{|c|c|c|c|c|c|c|}
\hline \multirow[t]{2}{*}{ Date } & \multicolumn{2}{|c|}{$J R G T$} & \multicolumn{2}{|c|}{$S L S$} & \multirow[b]{2}{*}{$\chi^{2}$} & \multirow[t]{2}{*}{ Overall melanic frequency } \\
\hline & $M^{c}$ & $M^{t}+M^{i}$ & $M^{c}$ & $M^{t}+M^{i}$ & & \\
\hline \multicolumn{7}{|c|}{ (a) Biston betularia } \\
\hline 1984-1985 & 66 & 11 & 75 & 6 & 1.95 & 89.2 \\
\hline 1986-1987 & 125 & 10 & 95 & 4 & 1.15 & 94.0 \\
\hline 1990-1991 & 24 & 10 & 39 & 18 & 0.05 & 69.2 \\
\hline 1992-1993 & 16 & 11 & 45 & 20 & 0.10 & 66.3 \\
\hline 1994-1998 & 12 & 14 & 15 & 26 & 0.61 & 40.3 \\
\hline 1999-2000 & 8 & 19 & 15 & 31 & 0.03 & 31.9 \\
\hline 2001-2006 & 3 & 15 & 1 & 15 & 0.89 & 11.8 \\
\hline Sum & & & & & 4.78 & \\
\hline Total & 287 & 120 & 252 & 89 & 1.49 & \\
\hline Heterogeneity & & & & & 3.29 & \\
\hline Date & $C^{n}$ & $C^{n m}$ & $C^{n}$ & $C^{n m}$ & $\chi^{2}$ & Overall melanic frequency \\
\hline \multicolumn{7}{|c|}{ (b) Odontoptera bidentata } \\
\hline $1984-1985$ & 9 & 8 & 38 & 30 & 0.05 & 55.3 \\
\hline 1986-1987 & 17 & 14 & 37 & 26 & 0.13 & 57.4 \\
\hline 1990-1991 & 7 & 11 & 5 & 21 & 2.07 & 27.3 \\
\hline 1992-1993 & 5 & 6 & 27 & 27 & 0.08 & 49.2 \\
\hline 1994-1995 & 4 & 2 & 7 & 6 & 0.28 & 57.9 \\
\hline 1998-1999 & 7 & 8 & 11 & 13 & 0.003 & 46.2 \\
\hline 2000-2002 & 4 & 9 & 11 & 18 & 0.20 & 35.7 \\
\hline 2001-2006 & 4 & 4 & 8 & 16 & 0.71 & 37.5 \\
\hline Sum & & & & & 3.52 & \\
\hline Total & 57 & 62 & 144 & 157 & 0.0001 & \\
\hline Heterogeneity & & & & & 3.52 & \\
\hline
\end{tabular}

Abbreviations: $\mathrm{C}^{\mathrm{n}}$, nigra; $\mathrm{C}^{\mathrm{nm}}$, non-melanic; $\mathrm{M}^{\mathrm{c}}$, carbonaria; $\mathrm{M}^{\mathrm{i}}$, insularia; $\mathrm{M}^{\mathrm{t}}$, typical.

This is a pattern that would be expected theoretically if insularia was intermediate in fitness between the other forms (Cook and Grant, 2000), which has been found at some other localities (Cook et al., 2004).

Odontoptera bidentata is less mobile than B. betularia, and is therefore more likely to show a difference between sites but, in both species, the pairs of data sets sample the same population or else the environment is forcing the same response. Either way, we are justified in combining the available data from the two sites for each species to show the general change in melanic frequencies in this part of Leeds (Figures 1 and 2). There has been a radical reduction in carbonaria frequency in $B$. betularia since the 1970s. The change in O. bidentata is also a definite decline, although it is less extreme. For both sites, some anomalous high or low frequencies are recorded, though for small sample sizes. Melanic frequency in this species has dropped more slowly than that of $B$. betularia in other industrial areas (Cook et al., 2002). For example, a location just south of Manchester had an apparently stable frequency of $68.9 \%$ nigra in the period 1972-1982 ( $n=1150$, Bishop et al., 1978; Cook et al., 2004), whereas in $1999-2006$, the frequency was $35.3 \%(n=90)$. As there is great variation about the trend in O. bidentata in Leeds, we confine our detailed analysis to B. betularia.

\section{Analysis of frequency change}

Various estimates of selection against the carbonaria form in B. betularia during its decline have been made (Grant et al., 1998; Cook et al., 2005 and earlier), all essentially based on projections from the earliest records in the sequence. These suggest $10-30 \%$ selection against it compared with typica. With the limited data sets available, however, it is difficult to separate the various

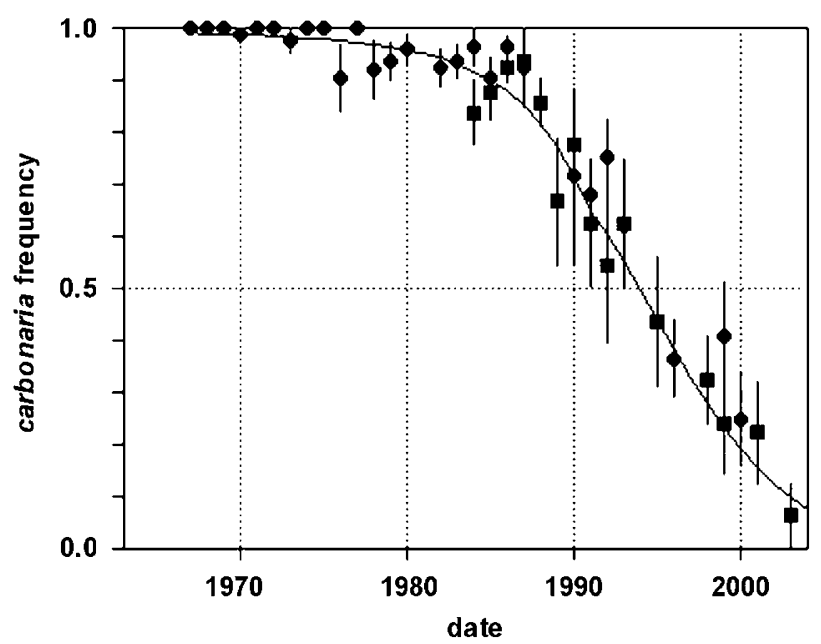

Figure 1 Frequency of the carbonaria form in Biston betularia for north Leeds. Circles: data of SLS (from Cook et al., 2005). Squares: this paper. Bars are \pm one standard error. The curve is the one discussed in the text, calculated backwards and forwards from 1991. Some adjacent small samples have been pooled.

processes involved. A new approach to the problem is suggested here. The moths have annual generations. The carbonaria form is dominant to typica and to insularia. If selection is the only systematic force that has a substantial effect on frequency, and fitness is dominant, then change in carbonaria frequency gives a direct indication of selection. Migration and mutation may also occur, but when selection is strong, and frequency spatially invariant, they will have little effect. When dominant morph frequency is very high, however, as at 
the start of the Leeds sequence, response to selection is strongly dependent on recessive morph frequency. Migration, therefore, has a magnified effect, especially if migrants have a very different frequency. If the starting frequency is extremely high, mutation may determine whether or not there is variation to select, and the sampling error effect is also magnified under these conditions. From the fact that the change, per generation, in gene frequency from migration is a linear function of $q$, whereas the change from natural selection is a cubic function of $q$, it follows that selection is at its most effective compared with migration near the middle of the frequency range; this is especially so if the area with a common pattern of selection is broad compared with migration distance. Instead of starting the estimation process from the initial observations, therefore, there is a case for considering frequencies in the centre of the frequency range as providing the best estimates of selection.

Under selection, the mapping function describing change from one generation to the next is

$$
q^{\prime}=q[1-s(1-q)] /\left[1-s\left(1-q^{2}\right)\right]
$$

where $q$ is the allele frequency of typicals, $s$ is the selective coefficient of the dominant melanic genotypes and $q^{\prime}$ the allele frequency after one generation. In this case, the starting carbonaria frequency is almost $100 \%$ and the trajectory drops to not far from zero. To find the value of $s$ that is least affected by migration, we suggest starting with frequencies that span the point of max-

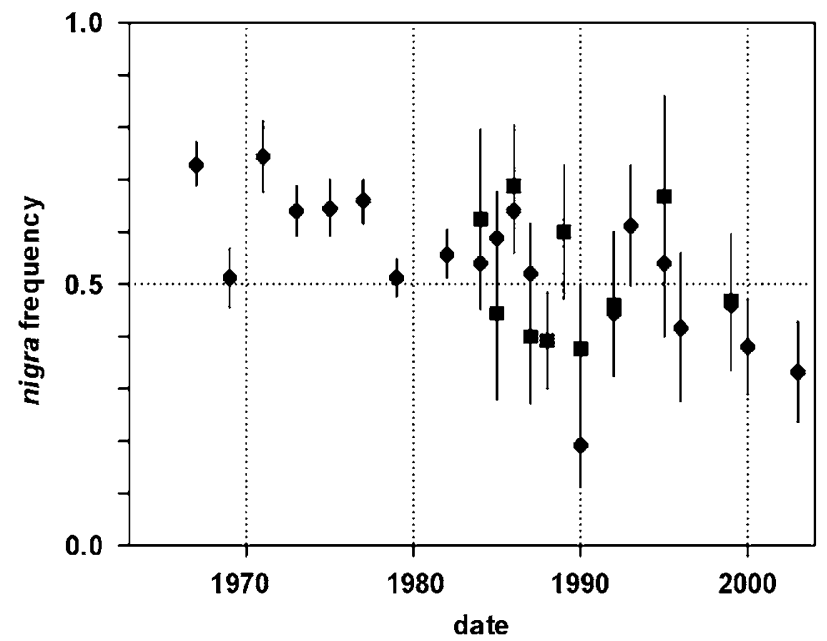

Figure 2 Frequency of the nigra form in Odontoptera bidentata for north Leeds. Circles: data of SLS (from Cook et al., 2005). Squares: this paper. Bars are \pm one standard error. Some adjacent small samples have been pooled. imum rate of change in frequency. This can be obtained by equating $\mathrm{d} \Delta q / \mathrm{d} q$ to zero, where $\Delta q=q^{\prime}-q$. When $s$ is small, this provides $q=2 / 3$, or a carbonaria frequency of 0.56. When selection is stronger, the point of maximum change is a function of $s$; for $s=0.3$, the equivalent carbonaria frequency is 0.60 . Therefore, we chose a frequency of carbonaria somewhat above 0.6 as a starting point to include the region of maximum change. Dates were chosen at which the frequency was about 0.7 (except in two cases where data points in this range were not available). The optimal starting frequency and the best estimate of $s$ were then found by iteratively minimizing the sum of squares of deviations with respect to both the initial frequency and the data points along the projected phenotype frequency curve. Convergence occurs roughly 1.4 times as fast for change in $s$ compared with change in initial frequency. The mean square at the point where the sum of squares of deviations is minimal is used as an estimate of the standard error of $s$.

Likewise, proceeding backwards the mapping function is

$$
q^{\prime \prime}=\{1-\sqrt{[1-4 t q(1-q)]}\} /[2 t(1-q)]
$$

where $t$ is the selective coefficient of typical relative to melanic (so that $s=-t /[1-t]), q$ is typical gene frequency as before and $q^{\prime \prime}$ is the gene frequency in the previous generation (this calculation works so long as $t<0$, so that melanics are at a disadvantage). We can then project the curve backwards towards an extreme starting frequency without making any further assumptions.

These procedures have been carried out for the Leeds data, with 1991 as a starting point within the period of maximum rate of change. This results in a 1991 frequency of 0.698 carbonaria and $s=0.233 \pm 0.074$ (Table 3, Figure 1). Projecting backwards provides $s=0.359 \pm 0.042$. This figure is higher than the later value, suggesting stronger selection, but the difference is not significant $(t=1.49)$.

Similar calculations have been carried out (Table 3) for data from Manchester (data of Cook et al., 1999), Caldy, west of Liverpool (Clarke et al., 1985, 1990, 1994; Grant et al., 1996), York (TJ Crawford in Cook et al., 2005, supplemented from Table 1), Cambridge (Lees and Creed, 1975; Majerus, 1998), north-west Kent (BK West, in Cook and Grant, 2000) and Nottingham (K Cooper in Cook and Grant, 2000). The estimates provide no significant evidence of change in selection over the period nor any consistent pattern of acceleration or deceleration, but most of the data sets are probably insufficiently complete to detect it. The series of records from Caldy, Wirral, close to Liverpool on the western edge of the north English industrial region, is

Table 3 Estimates of selection against the carbonaria form of Biston betularia for sequences of data from different parts of Britain using the

\begin{tabular}{|c|c|c|c|c|c|}
\hline Location & Early selection & Date & Initial estimate of carbonaria frequency & Late selection & $\mathrm{t}$-value \\
\hline Leeds & $0.359 \pm 0.042$ & 1991 & 0.698 & $0.233 \pm 0.074$ & 1.49 \\
\hline Manchester & $0.227 \pm 0.017$ & 1988 & 0.701 & $0.293 \pm 0.056$ & 1.13 \\
\hline Caldy (near Liverpool) & $0.226 \pm 0.025$ & 1981 & 0.698 & $0.199 \pm 0.024$ & 0.78 \\
\hline York & $0.184 \pm 0.081$ & 1991 & 0.735 & $0.187 \pm 0.065$ & 0.03 \\
\hline Nottingham & - & 1993 & 0.502 & $0.278 \pm 0.045$ & - \\
\hline Cambridge & $0.150 \pm 0.038$ & 1981 & 0.478 & $0.103 \pm 0.035$ & 0.93 \\
\hline North-west Kent & $0.085 \pm 0.012$ & 1983 & 0.702 & $0.170 \pm 0.033$ & 2.42 \\
\hline
\end{tabular}
method described

The $t$-values in the final column compare early and late estimates; none of them are significant. 
longer and based on larger samples than the others. The sequence from 1981 gives an estimate of $s=0.199 \pm 0.024$. The collection began in 1959 but a drop in frequency was not evident until 1969. Projecting back from 1981 to 1959 provides a curve that does not fit the data, whereas projection from 1981 to 1969 gives $s=0.226 \pm 0.025$. At least two phases are therefore suggested: the initial situation up to 1969 where carbonaria was not disadvantageous, followed by a period of strong selection that may then have decreased slightly in intensity with time. Clarke et al. (1985) point out that the frequency changes track the changing pattern of local atmospheric $\mathrm{SO}_{2}$ concentration. Similarly, the early period in Kent, from 1970 to 1980, may include the beginning of the decline there.

\section{Discussion}

In the area studied, the frequency of melanics in both $B$. betularia and $O$. bidentata declined over four decades. The rate of change differed between the two species, but for each of them it was the same at the two neighbouring sites. This is probably the first confirmation for melanic moths of the course of natural selection through replication at a pair of adjacent sites; it emphasizes the deterministic nature of industrial melanic dynamics. This evidence is important, given the use made of the peppered moth example in antievolutionary literature that has become part of the debate on biology teaching in American and British schools (Wells, 2000 and various creationist web sites; see Rudge, 2003; Majerus, 2005). As the changes cannot be ascribed to mutation pressure or random drift (because they would be insufficient) or to direct environmental influences on the developing phenotype (because the condition is known to be genetic), they must be driven by selection, although migration between sites also plays a critical role (Saccheri et al., in press).

Both the increase in carbonaria and its subsequent decline appear to be due to strong effects in heavily industrialized regions. When discussing Majerus (1998), in a review which soon became notorious, Coyne (1998) stated that the evolutionary significance of melanism is nearly always unknown. In fact, melanic variants are undoubtedly associated with local dark backgrounds in a wide variety of organisms, the classic example being Deer mice (Dice, 1947). Correlation between melanism and temporary or regular blackening by fire is seen in many species, ranging from Orthoptera (Hocking, 1964; Forsman and Appelqvist, 1999) to squirrels (Guthrie, 1967; Kiltie, 1989). Fire is a naturally recurring phenomenon and it is understandable that species should respond to the periodic selection it elicits. In the peppered moth, the increase in carbonaria (although not necessarily the less extreme insularia forms) appears to have required the special conditions of the eighteenth and nineteenth centuries, which resulted in large regions being blackened for a longer time than natural fire would do, but nevertheless still temporarily. Melanics appeared there first, followed by increase in less affected regions where they arrived by migration. Although these places sometimes offered conditions favourable to persistence of a low frequency of melanics, a threshold degree and extent of pollution appears to have been required to establish industrial melanism.

It should be emphasized that $B$. betularia is but one of many moth species with industrial melanics. Kettlewell
(1973) lists over 200 species with melanic variants, of which about $20 \%$ have shown higher frequencies of the melanics in industrial areas. Those for which more detailed information is available did not all respond in precisely the same way. O. bidentata melanics have never been as prevalent as those of $B$. betularia and fluctuated in frequency over shorter distances (Bishop et al., 1978; Cook and Jacobs, 1983). They have declined at a lower rate to frequencies that are sometimes still quite high (Cook et al., 2004, 2005; this paper). Apocheima pilosaria (Denis and Schiffermüller) is in some respects intermediate in response between these two species (Lees, 1971, 1981; Cook et al., 2002). Apamea crenata (Hufnagel) and Acronicta rumicis (L.) are species polymorphic throughout their ranges, but with dark forms at higher frequencies in conurbations (Bishop et al., 1976; West, 2000). Both have recently declined in frequency in builtup areas (West, 2000; Cook et al., 2005). B. betularia is not a model for all industrial melanism in moths.

The influence of migration on the geographic patterns of melanism is critical to our understanding of the changes. Unlike $O$. bidentata, $B$. betularia appears to have a relatively low density and to be highly mobile. If migration between regions of high and low frequency was sufficiently extensive, it would reduce the apparent selection at low carbonaria frequencies and inflate it where carbonaria was common, and could also change the apparent selection over time. The evidence used to date in modelling morph frequency variation suggests that males may move 2-3 km per generation (Bishop, 1972; May et al., 1975). As melanic frequency in rural and semirural areas was higher than expected, Bishop (1972) considered the possibility of heterozygote advantage as an additional contributory factor, and Mani (1980, 1990) included non-visual advantage to both melanic genotypes in his analysis of the north-Wales cline. These possibilities were earlier discussed by Ford (1937, 1953, 1964) and by Kettlewell $(1957,1973)$ from a different perspective. More recently, it was noted that, as is apparent with the present estimates (Figure 3), the systematic pressure reducing melanic frequency appears more intense where the frequency was initially higher (Cook et al., 1986; Grant et al., 1998; Cook, 2003). A logical conclusion could be that selective predation itself declines as the environment becomes more rural, thus removing the need for additional counteracting selective forces. There are some reasons why this could be so. Urban habitats, with fewer trees and numerous night-time lights, are likely to leave resting moths more exposed than rural ones. They may also have a higher density of insectivorous birds (Tratalos et al., 2008) and a lower density of moths (Cook et al., 2002). Under rural conditions, the moths may be more cryptic and the relative visibility of different morphs may be more similar (Mikkola, 1984; Howlett and Majerus, 1987; Liebert and Brakefield, 1987; Majerus et al., 2000). Even when forms differ in conspicuousness, the effect on frequency in the prey population must be small if the fraction discovered by predators is small.

Recent evidence, however, suggests that average migration distance is much larger, perhaps by an order of magnitude, than the figure used in these discussions (Saccheri et al., 2008). This leads to a major revision of our view of the role of the factors influencing frequency, and implies that strong selection against melanics occurs in 

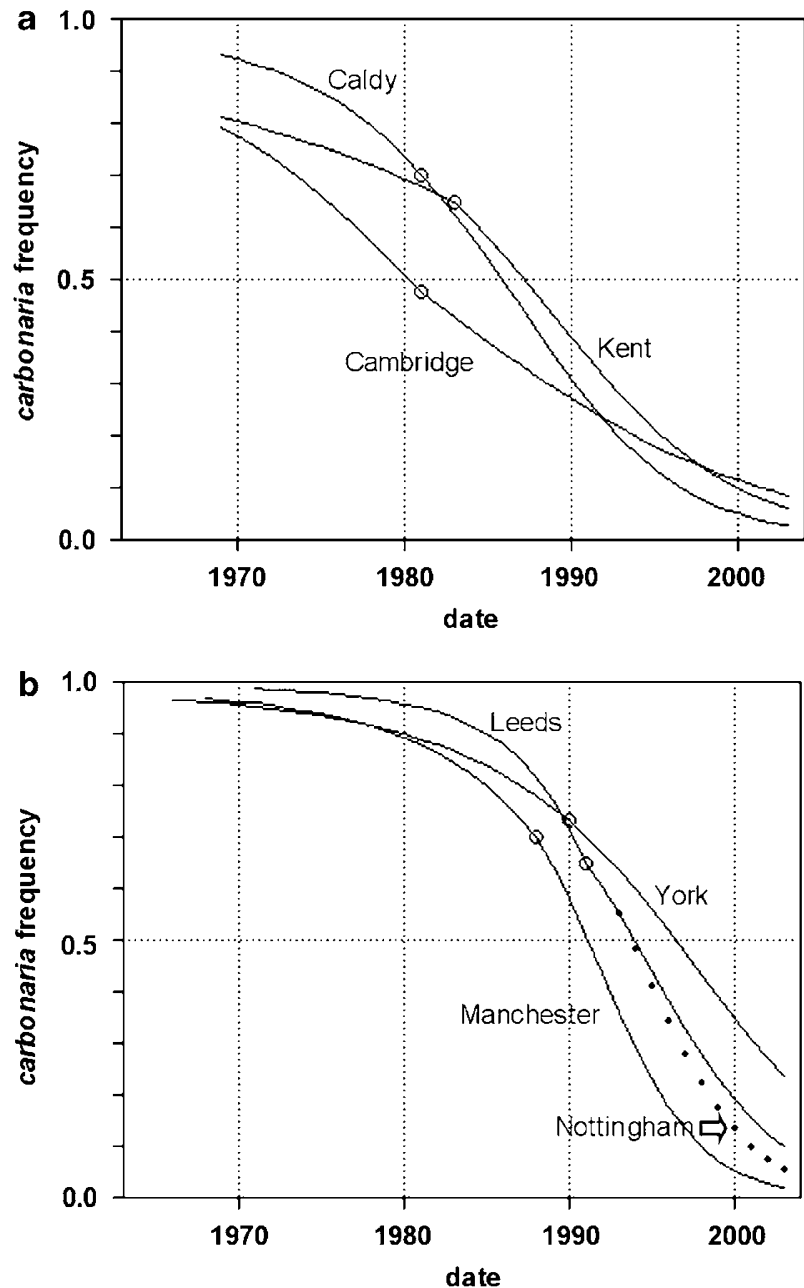

Figure 3 Curves generated from the estimates in Table 3. (a) Sites with relatively low selection against melanics in which the decline is apparent relatively early. (b) Sites in which melanics were more disadvantageous but decline in frequency is apparent later. Circles indicate points at which the estimates were initiated. The curve for Nottingham is shown as a series of points.

rural conditions. More experimental study of movement and selection is required. With a high migration rate, the frequency of melanics in an industrial area would be forced consistently downwards by swamping immigration from a rural area that had a high typical frequency. In addition $B$. betularia has a lower population density in urban areas than in the countryside (as do at least two other industrial melanics, Cook et al., 2002). This could enhance the power of immigration to reduce melanic gene frequency. Further, although our samples are not controlled for effort, Table 1 does give a strong suggestion that in this urban area, both our species have declined in numbers over the last quarter-century. It is likely that we have all underestimated the influence of variation in population density on the dynamics of changing gene frequencies.

\section{Conclusion}

It has been argued that the case of industrial melanism is not as important to the study of evolution as tradition would have us to believe (Rudge, 2005). However, the decline in industrial melanism, particularly in B. betularia, provides a unique example of an evolutionary change that has been observed over a wide geographical area. Unsurprisingly, the change is not spatially uniform (being earlier and slower in areas of initially lower frequency), and this heterogeneity increases as the spatial scale increases. At the 1-km scale, sampling sites replicate each other closely, whereas over a very wide area (seven locations sampled in a triangle of about $160 \times 300=24000 \mathrm{~km}^{2}$ ), there is an overall, consistent decline in the frequency of melanics. Because the effect is so consistent and so widespread, we can conclude with great confidence that it is due to natural selection. It is too rapid to be the result of mutation pressure, too consistent in what must be a total population size of at least many thousands of individuals to be the result of random drift, and too consistent in direction to result from migration acting alone, which at this scale would tend to even out melanic frequencies across the country, increasing those in rural areas while simultaneously decreasing those in the high-frequency industrial zone.

All this may be re-assuring, if not surprising, to evolutionary biologists. The system potentially provides scope for more detailed work on the way natural selection, migration and-so far rather neglectedspatial fluctuations in population size interact during the process of evolutionary change. For a wider audience, this study reinforces the view that, contrary to a much-repeated assertion among antievolutionists, evolutionary change has been directly observed and can be shown to result from natural selection.

\section{Acknowledgements}

JRGT is grateful for support from an honorary fellowship in the Faculty of Biological Sciences, University of Leeds, and LMC is grateful for support from the Manchester Museum, University of Manchester. We thank Ilik Saccheri for helpful discussion.

\section{References}

Bateson W (1900). Collective enquiry as to progressive melanism in moths-memorandum from the Evolution Committee of the Royal Society. Ent Record 12: 140.

Bishop JA (1972). An experimental study of the cline of industrial melanism in Biston betularia (L.) (Lepidoptera) between urban Liverpool and rural North Wales. J Anim Ecol 41: 209-243.

Bishop JA, Cook LM, Muggleton J (1976). Variation in some moths from the industrial north-west of England. Zool J Linn Soc 58: 273-296.

Bishop JA, Cook LM, Muggleton J (1978). The response of two species of moths to industrialization in northwest England. I. Polymorphisms for melanism. Phil Trans $R$ Soc Lond B 281: 491-515.

Clarke CA, Clarke FMM, Dawkins HC (1990). Biston betularia (the peppered moth) in West Kirby, Wirral, 1959-1989: updating the decline in f. carbonaria. Biol J Linn Soc 39: 323-326.

Clarke CA, Grant B, Clarke FMM, Asami T (1994). A long term assessment of Biston betularia (L.) in one UK locality (Caldy Common near West Kirby, Wirral) 1959-1993 and glimpses elsewhere. The Linnean 10: 18-26.

Clarke CA, Mani GS, Wynne G (1985). Evolution in reverse: clean air and the peppered moth. Biol J Linn Soc 26: 189-199. 
Cook LM (2003). The rise and fall of the carbonaria form of the peppered moth. Quart Rev Biol 78: 399-417.

Cook LM, Dennis RLH, Dockery M (2004). Fitness of insularia morphs of the peppered moth Biston betularia. Biol J Linn Soc 82: 359-366.

Cook LM, Dennis RLH, Mani GS (1999). Melanic frequency in the peppered moth in the Manchester area. Proc $R$ Soc Lond B 266: 293-297.

Cook LM, Grant BS (2000). Frequency of insularia during the decline in melanics in the peppered moth Biston betularia in Britain. Heredity 85: 580-585.

Cook LM, Jacobs TMGM (1983). Frequency and selection in the industrial melanic moth Odontoptera bidentata. Heredity 51: 487-494.

Cook LM, Mani GS, Varley ME. (1986). Postindustrial melanism in the peppered moth. Science 231: 611-613.

Cook LM, Muggleton J (2003). The peppered moth, Biston betularia (Linnaeus, 1758) (Lepidoptera: Geometridae), a matter of names. Ent Gazette 54: 211-221.

Cook LM, Riley AM, Woiwod IP (2002). Melanic frequencies in three species of moths in post industrial Britain. Biol J Linn Soc 75: 475-482.

Cook LM, Sutton SL, Crawford TJ (2005). Melanic moth frequencies in Yorkshire, an old English industrial hot spot. $J$ Hered 96: 522-528.

Coyne JA (1998). Not black and white. Nature 396: 35-36.

de Roode J (2007). The moths of war. New Sci 8: 46-49.

Dice LR (1947). Effectiveness of selection by owls of Deermice (Peromyscus maniculatus) which contrast in colour with their background. Cont Lab Vert Biol Univ Michigan 34: 1-20.

Doncaster L (1906). Collective enquiry as to progressive melanism in Lepidoptera. Ent Record 18: 165-168, 206-208, 222-276, 248-254.

Ford EB (1937). Problems of heredity in the Lepidoptera. Biol Rev 12: 461-503.

Ford EB (1953). The experimental study of evolution. Australian New Zealand Assn Adv Sci 28: 143-154.

Ford EB (1964). Ecological Genetics. Methuen: London, 335pp.

Forsman A, Appelqvist S (1999). Experimental manipulation reveals differential effects of colour pattern on survival in male and female pygmy grasshoppers. J Evol Biol 12: 391-401.

Grant BS, Cook AD, Clarke CA, Owen DF (1998). Geographic and temporal variation in the incidence of melanism in peppered moth populations in America and Britain. $J$ Hered 89: $465-471$.

Grant BS, Owen DF, Clarke CA (1996). Parallel rise and fall of melanic peppered moths in America and Britain. J Hered 87: 351-357.

Guthrie RD (1967). Fire melanism among mammals. Am Mid Nat 77: 227-230.

Haldane JBS (1924). A mathematical theory of natural and artificial selection. Trans Camb Phil Soc 23: 19-41.

Haldane JBS (1932). The Causes of Evolution. Longmans: London, 235pp.

Hocking B (1964). Fire melanism in some African grasshoppers. Evolution 18: 332-335.

Hooper J (2002). Of Moths and Men: an Evolutionary Tale. Fourth Estate: London, 377pp.

Howlett RJ, Majerus MEN (1987). The understanding of industrial melanism in the peppered moth (Biston betularia) (Lepidoptera: Geometridae). Biol J Linn Soc 30: 31-44.
Kettlewell HBD (1957). Industrial melanism in moths and its contribution to our knowledge of evolution. Proc R Institution 36: 1-14.

Kettlewell HBD (1973). The Evolution of Melanism. The Study of a Recurring Necessity. Oxford University Press: Oxford, 423pp.

Kiltie RA (1989). Wildfire and the evolution of dorsal melanism in fox squirrels. J Mammal 70: 726-739.

Lees DR (1971). The distribution of melanism in the pale brindled beauty moth, Phigalia pedaria, in Great Britain pp 152-174. In: Creed ER (ed). Ecological Genetics and Evolution. Blackwell: Oxford, 391pp.

Lees DR (1981). Industrial melanism: genetic adaptation of animals to air pollution. pp 129-176. In: Bishop JA and Cook LM (eds). Genetic Consequences of Man Made Change. Academic Press: London, 409pp.

Lees DR, Creed ER (1975). Industrial melanism in Biston betularia: the role of selective predation. I Anim Ecol 44: 67-83.

Liebert TG, Brakefield PM (1987). Behavioural studies on the peppered moth Biston betularia and a discussion of the role of pollution and lichens in industrial melanism. Biol J Linn Soc 31: 129-150.

Majerus MEN (1998). Melanism. Evolution in Action. Oxford University Press: Oxford, 338pp.

Majerus MEN (2005). Decline of a Darwinian disciple. In: Fellowes MDE, Holloway GJ, Rolff J (eds). Insect Evolutionary Ecology. CABI: Wallingford. pp 367-392.

Majerus MEN, Brunton CFA, Stalker J (2000). A bird's eye view of the peppered moth. J Evol Biol 13: 155-159.

Mani GS (1980). A theoretical study of morph ratio clines with special reference to melanism in moths. Proc $R$ Soc Lond $B$ 210: 299-316.

Mani GS (1990). Theoretical models of melanism in Biston betularia-a review. Biol J Linn Soc 39: 355-371.

May RM, Endler JA, McMurtrie RE (1975). Gene frequency clines in the presence of selection opposed by gene flow. Am Nat 109: 659-676.

Mikkola K (1984). On the selective forces acting in the industrial melanism of Biston and Oligia moths (Lepidoptera: Geometridae and Noctuidae). Biol J Linn Soc 21: 409-421.

Punnett RC (1915). Mimicry in Butterflies. Cambridge University Press: Cambridge, $188 \mathrm{pp}$.

Rudge DW (2003). Judith Hooper's Of Moths and Men: intrigue, tragedy and the peppered moth. J Hist Biol 36: 207-209.

Rudge DW (2005). Did Kettlewell commit fraud? Re-examining the evidence. Public Underst Sci 14: 249-268.

Saccheri IJ, Rousset F, Watts PC, Brakefield PM, Cook LM (2008). Selection and gene flow on a diminishing cline of melanic peppered moths. Proc Natl Acad Sci USA (in press).

Tratalos J, Fuller RA, Evans KL, Davies RG, Newson SE Greenwood JJD et al. (2008). Bird densities are associated with household densities. Global Change Biol 13: 1685-1695.

Turner JRG (2002). Natural and unnatural selection. Times Lit Supp 5183: 15.

Wells J (2000). Icons of Evolution: Science or Myth? Why Much of What we Teach about Evolution is Wrong. Regnery: Washington, DC, 356pp.

West BK (2000). Acronicta rumicis L. (Lep.: Noctuidae): the development and decline of melanism in north-west Kent. Ent Record 112: 205-206.

Wright S (1931). Evolution in Mendelian populations. Genetics 16: $97-159$. 